\title{
The diagnostic yield of open-access endoscopy of the upper gastrointestinal tract in the Netherlands
}

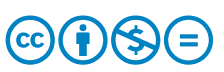

\author{
Authors \\ Institutions \\ 1 Department of Gastroenterology and Hepatology, \\ Northwest Clinics, Alkmaar, The Netherlands \\ 2 Department of Gastroenterology and Hepatology, \\ Academic Medical Centre, University of Amsterdam, \\ Amsterdam-Zuidoost, The Netherlands
}

Femke Crouwel' ${ }^{1}$, M. M. Meurs-Szojda ${ }^{1}$, M. Klemt-Kropp ${ }^{1}$, P. Fockens ${ }^{2}$, M. E. Grasman ${ }^{1}$ finding. submitted 1.6.2017

accepted after revision 26.10.2017

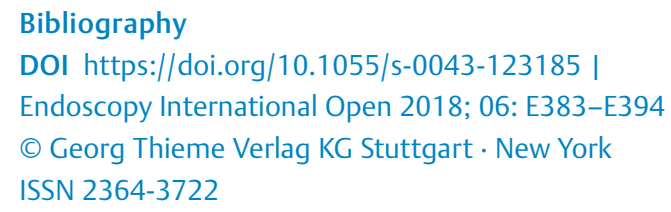

Corresponding author

Femke Crouwel, Noordwest Ziekenhuisgroep Gastroenterology and hepatology, Wilhelminalaan 12 Alkmaar 1815 JD, Netherlands

Fax: +0725484444

femke_crouwel@hotmail.com

\section{ABSTRACT}

Background and study aims Since the introduction of open-access esophago-gastroduodenoscopy (OAE) there is an increase in the total number of performed OAEs whilst the frequency of clinical relevant findings has decreased. The aim of this study was to assess the appropriate use and the diagnostic yield of OAE in the Netherlands and to determine which patient variables are able to predict a malignant

Patients and methods A retrospective chart review of all referrals for diagnostic OAE between October 2012 and October 2016 at the Northwest Clinics was performed. The indications were recorded from the referral letter and were classified as "appropriate" or "inappropriate" according to the NHG guideline. Logistic regression was used to detect significant predictive variables for a malignancy.

Results A total of 2006 patients were included, of whom $59.6 \%$ had an 'appropriate' referral indication. The diagnostic yield of finding a clinical relevant finding was significantly higher for OAEs with an "appropriate" referral indication. Independent risk factors for malignancy were alarm symptoms, age and male gender with a combined AUC of 0.868 . Conclusions Only $3.8 \%$ of the malignancies would be missed by strict adherence to the guideline. This indicates that the open-access system in the Netherlands works well. Further improvement of the system can be achieved by only accepting appropriate indications for OAE and by treating patients under the age of 40 without OAE. We showed that a risk-prediction model based on the variables age, alarm symptoms and male gender is a good predictor of malignant finding.

\section{Introduction}

Open-access esophago-gastroduodenoscopy (OAE) allows the general practitioner (GP) to refer patients for esophago-gastro-duodenoscopy without prior consultation of a gastroenterologist. OAE was introduced to decrease waiting time for patients who require urgent endoscopy, to decrease outpatient workload for gastroenterologists and to decrease costs related to endoscopy by eliminating potentially unnecessary officebased consultations. However, the introduction of OAE has resulted in an increase of the total number of performed endoscopies, leading to waiting list for patients requiring urgent endoscopy, whilst the frequency of clinically relevant findings has decreased [1-3]. In addition, although an esophago-gastro-duodenoscopy is relatively safe it is associated with potential complications and causes discomfort [4]. Therefore, unnecessary OAEs should be avoided.

To optimize use of an open-access system, guidelines for appropriate referral to OAE have been developed. Most studies of the diagnostic yields of OAE used American or British guidelines to examine the appropriateness of the OAE indication. These guidelines contain more indications than the Dutch College of General Practitioner guideline (NHG guideline) "upper abdominal complaints" [5-8]. The performed studies about the yield of OAE showed widely ranging non-adherence rates and also different rates of clinical relevant findings [3, 4, 8-10]. 
- Table 1 Referral indications divided in 4 groups, of which the first three groups are considered appropriate referral indications and the last group is considered inappropriate according to the NHG guideline.

\begin{tabular}{|c|c|c|c|}
\hline \multicolumn{4}{|l|}{ Referral indications } \\
\hline Alarm symptoms & Follow-up & $\begin{array}{l}\text { Other referral indications according to } \\
\text { the guideline }\end{array}$ & $\begin{array}{l}\text { Referral indications not mentioned in } \\
\text { the guideline }\end{array}$ \\
\hline Dysphagia & $\begin{array}{l}\text { Follow-up of gastric } \\
\text { ulcer healing }\end{array}$ & $\begin{array}{l}\text { Persistent or recurrent dyspepsia older than } \\
\text { age } 50 \text { with a negative } H \text {. pylori status }\end{array}$ & $\begin{array}{l}\text { Dyspepsia younger than age } 50 \text { without } \\
\text { alarm symptoms }\end{array}$ \\
\hline Unexplained weight loss & & $\begin{array}{l}\text { First-degree relative older than age } 40 \text { of a } \\
\text { patient with familial gastric cancer }\end{array}$ & $\begin{array}{l}\text { Persistent or recurrent dyspepsia older than } \\
\text { age } 50 \text { with unknown } \mathrm{H} \text {. pylori status }\end{array}$ \\
\hline Gastrointestinal bleeding & & & Familial esophageal cancer \\
\hline Anemia & & & Reassurance \\
\hline Persistent vomiting & & & \\
\hline
\end{tabular}

Some studies tried to identify subgroups which are at risk of malignant disease. It was shown that age, male gender, smoking and alarm symptoms were independent predictors of malignancy but their accuracy is controversial $[11,12]$.

Due to the absence of studies wherein the Dutch NHG guideline is used, the uncertainty about the diagnostic yield in the Netherlands and the vagueness about which subgroups in the Netherlands have the largest a priori probability of malignancy. The aim of this study was to assess the following questions; what is the appropriateness of referral according to the NHG guideline 'upper abdominal complaints'? What is the diagnostic yield of OAE in the Netherlands? Which subgroups have the greatest yield of OAE? An answer to these questions is even more important in the era of evidence-based medicine, growing efficacy and cost-effectiveness. Furthermore, the capacity for endoscopic examinations is limited and therefore the need to avoid unnecessary OAE is of paramount importance.

\section{Patients and methods}

A retrospective chart review of all referrals for diagnostic OAE between October 2012 and October 2016 at the Northwest Clinics, location Alkmaar was performed. All patients who underwent an OAE were included and patients younger than eighteen years or with an incomplete endoscopy (not due to a stenosis) were excluded from further analysis.

The indications for OAE were collected from the referral letter. The NHG guideline "upper abdominal complaints" was used to determine the appropriateness of the indication for endoscopy ( $>$ Table 1 ). According to the guideline, reassurance was an appropriate indication for OAE, although in this study it was classified as an inappropriate indication, because all OAEs are performed for some sort of reassurance, for the patient or for the GP.

The referral indications were divided into 4 groups; alarm symptoms, follow-up, other referral indications according to the guideline and referral indications not mentioned in the guideline ( $>$ Table 1 ). The first 3 categories are considered appropriate and the last category is considered inappropriate according to the NHG guideline.
Alarm symptoms were considered the most clinical relevant when present and patients with any of these symptoms were classified in the category alarm symptoms, irrespective of any other dyspeptic symptoms.

Referrals were screened by a gastroenterologist and they determined the time frame during which the OAE was performed, but even in the absence of an appropriate indication OAE was performed

The OAEs were performed by an experienced gastroenterologist or by a gastroenterologist in training under the supervision of an experienced gastroenterologist. Endoscopic findings were reported in a digital reporting system (Endobase ${ }^{\odot}$, Olympus, Zoeterwoude, The Netherlands) with, whenever possible, internationally accepted terminology and definitions (Forrest classification for ulcer bleeding, Los Angeles classification for erosive esophagitis and the Prague C\&M classification for a Barrett's esophagus).

Endoscopic findings were classified into 3 categories; malignant, benign with clinical relevance and benign without clinical relevance. A finding was considered clinically relevant if there was impact on therapeutic decisions and prognosis, wherein it was assumed that patients used a proton pump inhibitor (PPI) or an $\mathrm{H} 2$ receptor antagonist ( $\mathrm{H} 2 \mathrm{RA}$ ) in an adequate dose as described in the NHG guideline "upper abdominal complaints." Malignancies found during OAE were classified into the category malignant. To classify the other diagnosis, the patient file was reviewed to examine whether the outcome of the $\mathrm{OAE}$ changed the therapeutic decisions or prognosis. If that was the case patients were classified into the category benign with clinical relevance.

When multiple endoscopic findings were present, patients were included for statistical analysis in the most relevant group, wherein it was assumed that the group malignant was the most relevant.

Besides the referral indication other variables which were possibly associated with the outcome of the endoscopy were collected, such as: age, gender, treatment with PPI or H2RA and Helicobacter pylori status. 


\section{Statistical analysis}

Patients with appropriate indications were compared with those with an inappropriate indication to assess the association between the appropriateness of the referral indication and the presence of clinically relevant endoscopic diagnoses (malignant and benign with clinical relevance). The extent of this association was calculated with univariate logistic regression analysis.

Logistic regression analyses were performed on predictor variables with a $P$ value $<0.2$ in the univariate analysis, using a forward method procedure with a cut-off $P$ value of 0.05 .

The ability of the NHG guideline to predict relevant endoscopic diagnoses was determined by calculating the relative risk and positive and negative predictive value for each separate referral indication and for all indications combined.

To find out which subgroup of patients has the highest risk of a upper gastrointestinal malignancy a logistic regression analysis was performed, were tested for different factors influencing the finding of a malignancy. The receiver operating characteristics (ROC) curve with the area under the curve (AUC) was used to describe the performance of these factors. The statistical difference between these AUCs of the dependent ROC curves was calculated with the method of DeLong et al. using MedCalc (MedCalc Software, Mariakerke, Belgium).

Internal validation of the prediction model for upper gastrointestinal malignancies found by the logistic regression model was done by bootstrap resampling (1000 bootstrap samples).

Nominal and ordinal variables were described as numbers with percentages. Continuous variables were described as means with standard deviations in case of a normal distribution and as median with interquartile range in case of a skewed distribution. Normality was tested with Kolmogorov-Smirnov test. Independent Student's t-tests were used to analyze continuous outcome variables and logistic regression analyses were used for dichotomous outcome variables. Differences were considered significant at a $5 \%$ probability level.

Statistical analyses were conducted using Statistical Package for Social Sciences (SPSS ${ }^{\circledR}$, IBM, New York, United States of America) version 20.

\section{Results}

\section{Baseline characteristics}

A total of 2006 OAEs were performed during the study period. Of these patients, 1088 were women (54.2\%) and 918 were men $(45.8 \%)$. The median ( \pm IQR) age of the participants was $60 \pm 20$ years (range $18-92$ years). In total 1478 (73.7\%) used a PPI or H2RA before the OAE was performed. The $\mathrm{H}$. pylori status was known for 611 patients prior to the OAE (30.5\%) of whom 6 patients tested positive (0.3\%). In 100 patients (4.9\%) showed the biopsies, or the test done after the endoscopy that they were infected with $\mathrm{H}$. pylori. 979 patients had an unknown $\mathrm{H}$. pylori status (48.8\%). Any form of sedation with midazolam or alfentanil was used in 774 patients (38.6\%).

\section{Referral indication}

The indication for OAE was considered appropriate, according to the NHG guideline, in $59.6 \%$ of the cases (1195 patients). The main indication in this group was dysphagia in 420 patients (35.1\%). The main inappropriate indication was dyspeptic symptoms in 427 patients (52.7\%) older than 50 years without a $\mathrm{H}$. pylori status. All referral indications are summarized in

- Table 2 .

\section{Endoscopic finding}

A malignancy in the upper gastrointestinal tract was detected in 104 examinations (5.2\%) of which the majority was found to be an esophageal carcinoma $(n=82 ; 4.1 \%)$. An endoscopic finding classified as benign with clinic relevance was found in 388 patients (19.3\%), of these findings a Barrett's esophagus accounted for $6.4 \%$ (129 patients). A not clinically relevant finding and a normal examination occurred in $39.5 \%$ and $36 \%$ of the cases, respectively. All endoscopic findings are summarized in Table 3.

\section{Diagnostic yield}

The diagnostic yield was significantly higher for OAEs with a referral indication according to the NHG guideline. Of the 492 patients with clinical relevant endoscopic findings, $74 \%$ had an appropriate referral indication (OR 2.337 [95\% Cl 1.8662.928]; $P<0.0001)$. Significant predictive variables for a clinical relevant finding at OAE found by multinomial logistic regression analysis were a referral indication according to the NHG guideline, age, male gender and a positive $\mathrm{H}$. pylori status ( $\triangleright$ Table 4). A sensitivity analysis with age divided in equal quartiles showed that the significance of age as predictive variable is based on the last quartile (69 years and older) $(P<$ 0.0001 ).

The diagnostic yield of finding a malignancy in the upper gastrointestinal tract was also significantly higher in patients with an appropriate referral indication (OR $18.425[95 \% \mathrm{Cl}$ $6.754-50.260]$; $P<0.0001)$. The relative risk of finding a malignancy in patients with alarm symptoms was 14.26 ( $>$ Table 2). Especially dysphagia, weight loss and dysphagia with weight loss combined were associated with a malignancy diagnosed with endoscopy. In contrast, the appropriate referral indication: 'dyspepsia in patients $>50$ years of age with a negative $\mathrm{H}$. pylori status' had a low diagnostic yield of finding a malignancy. 4 patients above 50 years of age with dyspeptic symptoms and an unknown $\mathrm{H}$. pylori status had a malignancy ( $\triangleright$ Table 2 ). The characteristics of these 4 patients with malignant disease are shown in $>$ Table 5 .

The sensitivity, specificity, PPV and NPV for all referral indication are summarized in $>$ Table 6 .

Besides the malignancies in the upper gastrointestinal tract, more frequently detected findings with clinical relevance in appropriate OAEs were; reflux esophagitis grade D, esophageal candidiasis and hiatal hernia ( $\triangleright$ Table3). 
- Table 2 Relative risk of finding a malignancy, a benign finding with clinical relevance and a benign finding without clinical relevance for every referral indication. Wherein patients with the referral indication are compared to patients without the referral indication.

\begin{tabular}{|c|c|c|c|c|c|c|c|}
\hline \multicolumn{8}{|c|}{ Outcome of endoscopy } \\
\hline \multirow{2}{*}{$\begin{array}{l}\text { Referral } \\
\text { indication }\end{array}$} & \multirow[t]{2}{*}{$\mathrm{N}(\%)$} & \multicolumn{2}{|l|}{ Malignant } & \multicolumn{2}{|c|}{ Benign with clinical relevance } & \multicolumn{2}{|c|}{ Benign without clinical relevance } \\
\hline & & n (\%) & $\operatorname{RR}(95 \% \mathrm{CI})$ & $n(\%)$ & $\mathrm{RR}(95 \% \mathrm{Cl})$ & $\mathrm{n}(\%)$ & $\mathrm{RR}(95 \% \mathrm{Cl})$ \\
\hline $\begin{array}{l}\text { Indication accord- } \\
\text { ing to the NHG } \\
\text { guideline }\end{array}$ & $1195(59.6 \%)$ & $100(5.0 \%)$ & $17.0(6.3-45.91)^{1}$ & $264(13.2 \%)$ & $1.44(1.19-1.75)^{1}$ & $831(41.4 \%)$ & $0.83(0.79-0.87)^{1}$ \\
\hline $\begin{array}{l}\text { Alarm symptoms } \\
\text { overall }\end{array}$ & $797(39.7 \%)$ & $94(4.7 \%)$ & $14.26(7.48-27.20)^{1}$ & $200(10.0 \%)$ & $1.61(1.35-1.93)^{1}$ & $503(25.0 \%)$ & $0.75(0.71-0.80)^{1}$ \\
\hline Dysphagia & $420(20.9 \%)$ & $38(1.9 \%)$ & $2.17(1.48-3.19)^{1}$ & $113(5.6 \%)$ & $1.55(1.28-1.88)^{1}$ & $269(13.4 \%)$ & $0.82(0.76-0.88)^{1}$ \\
\hline Weight loss & $104(5.2 \%)$ & $10(0.5 \%)$ & $1.95(1.05-3.62)^{1}$ & $21(1.0 \%)$ & $1.05(0.71-1.55)$ & $73(3.7 \%)$ & $0.93(0.82-1.05)$ \\
\hline $\begin{array}{l}\text { Gastrointestinal } \\
\text { bleeding }\end{array}$ & $92(4.6 \%)$ & $4(0.2 \%)$ & $0.83(0.31-2.21)$ & $22(1.1 \%)$ & $1.25(0.86-1.82)$ & $66(3.3 \%)$ & $0.95(0.83-1.08)$ \\
\hline Anaemia & $31(1.5 \%)$ & $2(0.1 \%)$ & $1.25(0.32-4.84)$ & $9(0.4 \%)$ & $1.51(0.87-2.64)$ & $20(1 \%)$ & $0.85(0.66-1.11)$ \\
\hline $\begin{array}{l}\text { Dysphagia and } \\
\text { weight loss }\end{array}$ & $121(6.0 \%)$ & $34(1.7 \%)$ & $7.57(5.25-10.91)^{1}$ & $28(1.4 \%)$ & $1.21(0.86-1.70)$ & $59(2.9 \%)$ & $0.64(0.54-0.78)^{1}$ \\
\hline $\begin{array}{l}\text { Weight loss and } \\
\text { gastrointestinal } \\
\text { bleeding }\end{array}$ & $12(0.6 \%)$ & $1(0.05 \%)$ & $1.61(0.24-10.64)$ & $4(0.2 \%)$ & $1.73(0.77-3.87)$ & $7(0.35 \%)$ & $0.77(0.48-1.25)$ \\
\hline $\begin{array}{l}\text { Dyspepsia } \\
>50 \text { years of age, } \\
\text { HP negative }\end{array}$ & $383(19.1 \%)$ & $6(0.4 \%)$ & $0.26(0.11-0.59)^{1}$ & $62(3.5 \%)$ & $0.81(0.63-1.03)$ & $315(15.2 \%)$ & $1.11(1.05-1.18)^{1}$ \\
\hline Other & $32(1.6 \%)$ & $5(0.25 \%)$ & $3.12(1.36-7.13)^{1}$ & $5(0.25 \%)$ & $0.81(0.36-1.81)$ & $22(1.1 \%)$ & $0.91(0.72-1.15)$ \\
\hline $\begin{array}{l}\text { Indication not } \\
\text { according to the } \\
\text { NHG guideline }\end{array}$ & $811(40.4 \%)$ & $4(0.2 \%)$ & $0.06(0.02-0.16)^{1}$ & $124(6.2 \%)$ & $0.69(0.57-0.84)^{1}$ & $683(34.0 \%)$ & $1.21(1.15-1.27)^{1}$ \\
\hline $\begin{array}{l}\text { Dyspepsia } \\
<50 \text { years of age }\end{array}$ & $373(18.6 \%)$ & $0(0 \%)$ & $0.02(0.00-0.34)^{1}$ & $39(1.9 \%)$ & $0.49(0.36-0.67)^{1}$ & $334(16.7 \%)$ & $1.24(1.18-1.30)^{1}$ \\
\hline $\begin{array}{l}\text { Dyspepsia } \\
>50 \text { years of age, } \\
\text { HP unknown }\end{array}$ & $427(21.3 \%)$ & $4(0.2 \%)$ & $0.15(0.05-0.40)^{1}$ & $82(4.2 \%)$ & $0.99(0.80-1.23)$ & $341(16.9 \%)$ & $1.08(1.02-1.14)^{1}$ \\
\hline Other & $11(0.5 \%)$ & $0(0 \%)$ & $0.80(0.05-12.08)$ & $3(0.1 \%)$ & $1.41(0.54-3.73)$ & $8(0.4 \%)$ & $0.96(0.67-1.38)$ \\
\hline Total & $2006(100 \%)$ & $104(5.2 \%)$ & & $388(19.3 \%)$ & & $1514(75.5 \%)$ & \\
\hline
\end{tabular}

\section{Risk-predictive model}

To find out which subgroup of patients has the greatest risk of a malignancy in the upper gastrointestinal tract a multinomial logistic regression analysis ( $>$ Table 7 ) was performed, which showed that significant predictive variables for a malignant finding at OAE were; male gender, alarm symptoms and age. A sensitivity analysis with age divided in equal quartiles showed that the significance of age as predictive variable is based on the last 2 quartiles (60 years and older) $(P<0.001)$.

No malignancies were found in patients $<40$ years of age while it was uncommon in patients under 45 years of age, whereas in this patient group many OAEs were performed
( $\triangleright$ Fig. 1 and $\triangleright$ Fig. 2). In women under the age of 50 years no malignancies of the upper gastrointestinal tract were detected ( $\triangleright$ Fig. 1 and $\triangleright$ Fig. 2 ).

The ROC curve ( $\boldsymbol{\text { Fig. }} \mathbf{3}$ ) showed that age alone $(\mathrm{AUC}=0.729$ [95\% Cl $0.687-0.771])$ was significantly $(P<0.0001)$ less accurate in predicting a malignant finding than our risk prediction model (age, male gender and alarm symptoms combined) (AUC $=0.868$ [95\% Cl $0.841-0.894]$ ). Also alarm symptoms alone $(A \cup C=0.767$ [ $95 \% \mathrm{Cl} 0.729-0.805]$ ) was less accurate in predicting a malignant finding than the combination of the 3 factors ( $>$ Fig. 3 ).

Internal validation of the predicting model with bootstrap resampling showed a corrected AUC of 0.867 . 
- Table 3 Odds ratio of different endoscopic outcomes in OAEs performed for an appropriate referral indication.

\begin{tabular}{|c|c|c|c|c|c|c|}
\hline Outcome of OAE & $\begin{array}{l}\text { Number of } \\
\text { patients (\%) }\end{array}$ & $\begin{array}{l}\text { Appropriate re- } \\
\text { ferral indication, } \\
\text { n (\%) }\end{array}$ & $\begin{array}{l}\text { Inappropriate } \\
\text { referral indica- } \\
\text { tion, } \mathrm{n}(\%)\end{array}$ & OR & $95 \% \mathrm{Cl}$ & $P$ value \\
\hline Malignant & $104(5.2 \%)$ & $100(5 \%)$ & $4(0.2 \%)$ & 18.425 & $6.754-50.260$ & $<0.0001$ \\
\hline Esophageal carcinoma & $82(4.1 \%)$ & $79(3.9 \%)$ & $3(0.2 \%)$ & 19.066 & $5.998-60.601$ & $<0.0001$ \\
\hline Malignancies of the stomach & $21(1.05 \%)$ & $20(1 \%)$ & $1(0.05 \%)$ & 13.787 & $1.847-102.935$ & 0.011 \\
\hline Malignant tumors of the duodenum & $1(0.05 \%)$ & $1(0.05 \%)$ & $0(0 \%)$ & & & \\
\hline Benign with clinical relevance & $388(19.3 \%)$ & $264(13.2 \%)$ & $124(6.1 \%)$ & 1.571 & $1.242-1.987$ & $<0.0001$ \\
\hline Reflux esophagitis grade A & $12(0.6 \%)$ & $5(0.25 \%)$ & $7(0.35 \%)$ & 0.483 & $0.153-1.526$ & 0.215 \\
\hline Reflux esophagitis grade B & $15(0.7 \%)$ & $6(0.28 \%)$ & $9(0.42 \%)$ & 0.450 & $0.159-1.268$ & 0.131 \\
\hline Reflux esophagitis grade $C$ & $37(1.8 \%)$ & $23(1.1 \%)$ & $14(0.7 \%)$ & 1.117 & $0.571-2.184$ & 0.746 \\
\hline Reflux esophagitis grade D & $29(1.4 \%)$ & $25(1.2 \%)$ & $4(0.2 \%)$ & 4.311 & $1.495-12.434$ & 0.007 \\
\hline Barrett esophagus & $129(6.4 \%)$ & $73(3.6 \%)$ & $56(2.8 \%)$ & 0.877 & $0.612-1.258$ & 0.476 \\
\hline Esophageal candidiasis & $30(1.6 \%)$ & $24(1.3 \%)$ & $6(0.3 \%)$ & 2.750 & $1.119-6.757$ & 0.027 \\
\hline Hiatal hernia & $22(1.1 \%)$ & $19(0.95 \%)$ & $3(0.15 \%)$ & 4.351 & $1.283-14.753$ & 0.018 \\
\hline Ulcus ventriculi & $20(1 \%)$ & $16(0.8 \%)$ & $4(0.2 \%)$ & 2.738 & $0.912-8.219$ & 0.073 \\
\hline Gastritis & $19(0.9 \%)$ & $13(0.6 \%)$ & $6(0.3 \%)$ & 1.476 & $0.559-3.898$ & 0.432 \\
\hline Ulcus duodeni & $17(0.8 \%)$ & $12(0.6 \%)$ & $5(0.2 \%)$ & 1.635 & $0.574-4.659$ & 0.357 \\
\hline Other & $58(2.9 \%)$ & $48(2.4 \%)$ & $10(0.5 \%)$ & 3.352 & $1.686-6.665$ & 0.001 \\
\hline Benign without clinical relevance & $1514(75.5 \%)$ & $831(41.4 \%)$ & $683(34.1 \%)$ & 0.428 & $0.342-0.536$ & $<0.0001$ \\
\hline Reflux esophagitis grade A & $152(7.6 \%)$ & $79(3.9 \%)$ & $73(3.7 \%)$ & 0.716 & $0.514-0.997$ & 0.048 \\
\hline Reflux esophagitis grade B & $94(4.7 \%)$ & $47(2.3 \%)$ & $47(2.3 \%)$ & 0.666 & $0.440-1.007$ & 0.054 \\
\hline Schatzki ring & $42(2.1 \%)$ & $38(1.9 \%)$ & $4(0.2 \%)$ & 6.626 & $2.356-18.638$ & $<0.0001$ \\
\hline Hiatal hernia & $236(11.7 \%)$ & $128(6.4 \%)$ & $108(5.3 \%)$ & 0.781 & $0.594-1.026$ & 0.076 \\
\hline Fundic gland polyposis & $48(2.4 \%)$ & $29(1.4 \%)$ & $19(1 \%)$ & 1.037 & $0.577-1.862$ & 0.904 \\
\hline Gastritis & $176(8.7 \%)$ & $99(4.9 \%)$ & $77(3.8 \%)$ & 0.861 & $0.630-1.176$ & 0.348 \\
\hline Duodenitis & $40(2.0 \%)$ & $22(1.1 \%)$ & $18(0.9 \%)$ & 0.826 & $0.440-1.550$ & 0.552 \\
\hline Normal & $722(36.0 \%)$ & $385(19.2 \%)$ & $337(16.8 \%)$ & 0.669 & $0.556-0.804$ & $<0.0001$ \\
\hline Other & $4(0.3 \%)$ & $4(0.3 \%)$ & $0(0 \%)$ & & & \\
\hline Total & $2006(100 \%)$ & $1195(59.6 \%)$ & $811(40.4 \%)$ & & & \\
\hline
\end{tabular}

\section{Discussion}

Since the introduction of OAE an increase in the number of performed endoscopies has been reported, whilst the frequency of clinically relevant findings has decreased $[1,2]$. This results in waiting lists leading to delayed endoscopy for those with a potential malignant disease [3]. The appropriateness of the referral and the diagnostic yield of OAEs is, therefore, an important issue. To our knowledge, this is the first surveys on the diagnostic yield of OAEs in the Netherlands in which the NHG guideline "upper abdominal complaints" was used.
The most prominent finding in our study was the high frequency of malignancies compared to other studies. In our cohort a prevalence of $5.2 \%$ was found, whilst in a meta-analysis (57,363 patients) a prevalence of upper Gl cancer of $0.8 \%$ was found [13]. The high frequency of malignancies in our study cannot be explained by patient selection and the prevalence of upper gastrointestinal cancers in the Netherlands is comparable to other Western countries [14]. We speculate that the difference can be explained by the use of the brief NHG guideline and the good primary health care services in the Netherlands.

In our study the rate of patients referred for OAE with an indication not according to the NHG guideline was $40.4 \%$. In 
- Table4 Uni- and multivariate logistic regression analysis of possible predictors for a clinical relevant endoscopy outcome.

\begin{tabular}{|c|c|c|c|c|c|c|}
\hline \multirow[b]{2}{*}{ Possible predictors } & \multicolumn{3}{|c|}{ Univariate analyse } & \multicolumn{3}{|c|}{ Multivariate analyse } \\
\hline & OR & $95 \% \mathrm{Cl}$ & $P$ value & OR & $95 \% \mathrm{Cl}$ & $P$ value \\
\hline Appropriate referral indication & 2.337 & $1.866-2.928$ & $<0.0001$ & 1.565 & $1.075-2.280$ & 0.020 \\
\hline Age & 1.037 & $1.029-1.045$ & $<0.0001$ & 1.023 & $1.010-1.037$ & 0.001 \\
\hline \multicolumn{7}{|l|}{ Gender } \\
\hline - Female & Reference & & & & & \\
\hline - Male & 2.071 & $1.684-2.547$ & $<0.0001$ & 1.785 & $1.306-2.438$ & $<0.0001$ \\
\hline \multicolumn{7}{|l|}{$\mathrm{PPI}$ or H2RA use } \\
\hline - Yes & Reference & & & & & \\
\hline - No & 1.817 & $1.445-2.285$ & $<0.0001$ & 1.292 & $0.877-1.903$ & 0.195 \\
\hline \multicolumn{7}{|l|}{ HP status } \\
\hline - Negative & Reference & & & & & \\
\hline - Positive & 2.724 & $1.786-4.154$ & $<0.0001$ & 2.767 & $1.757-4.357$ & $<0.0001$ \\
\hline \multicolumn{7}{|l|}{ Sedation } \\
\hline - Yes & 0.900 & $0.728-1.113$ & 0.332 & & & \\
\hline - No & Reference & & & & & \\
\hline
\end{tabular}

- Table 5 Details of the 4 patients with malignant disease without a referral indication according to the guideline.

\begin{tabular}{|c|l|l|l|l|l|l|l|}
\hline No & Gender & Age & Sedation & PPI or H2RA use & H. pylori status & Referral indication & Diagnosis \\
\hline $\mathbf{1}$ & Woman & 81 & No & Yes & Unknown & Nausea & Esophageal carcinoma \\
\hline $\mathbf{2}$ & Man & 80 & Unknown & Yes & Unknown & Epigastric pain & Esophageal carcinoma \\
\hline 3 & Man & 69 & No & Yes & Unknown & Epigastric pain & Esophageal carcinoma \\
\hline 4 & Woman & 70 & No & Yes & Negative & Cough & Malignancy of the stomach \\
\hline
\end{tabular}

other studies the rate of inappropriate referrals ranged from $11.7 \%$ till $77.2 \%[4,9,10]$. The greater guideline compliance in some studies can possibly be explained by a lecture series for the GPs prior to the data collection [8]. This gives the impression that educational programs dedicated to GPs can improve the effectiveness of an open-access system. However, due to the use of different guideline as benchmarks these data are not comparable with our results.

In the present study, the diagnostic yield of OAE was statistically significant higher for endoscopies with a referral indication according to the NHG guideline $(P<0.0001)$. The sensitivity and specificity of the NHG guideline to detect a malignancy was $96.2 \%$ and $42.4 \%$. For detecting a clinically relevant finding it was $68.0 \%$ and $42.5 \%$, respectively. These data are concordant with a meta-analysis which showed an adjusted sensitivity and specificity of the ASGE guidelines for clinical relevant findings of $85 \%$ and $28 \%$ [15]. Despite the relatively high sensitivity, the frequency of a clinical relevant finding in patients with an inappropriate referral indication was $15.8 \%$ in our study, which is a low frequency compared to other studies (ranging from $23 \%$ till 66\%) [16-18].

In our study only 4 (3.8\%) of the 104 malignancies would be missed by strict adherence to the guideline, therewith substantially lower than the $8 \%$ in the study of Rossi et al. [19]. This can be explained by the high sensitivity (96.2\%) of the NHG guideline in our study for detecting malignancies. But the fact remains that by strict adherence to the guideline some malignancies could be missed. That is why some authors were stating that the appropriateness criteria should not be the only factor in the decision-making process [20]. That is the reason that the Dutch NHG guideline states that a GP might consider to perform a OAE for reassurance.

In this study $20.8 \%$ of the referral indication were classified as 'inappropriate' due to an unknown $\mathrm{H}$. pylori status in patients with dyspepsia above the age of 50 . Of these patients 4 $(0.2 \%)$ had a malignant finding and $82(4.0 \%)$ a benign finding with clinical relevance. Epidemiologic studies have shown that individuals infected with $\mathrm{H}$. pylori have an increased risk of gastric adenocarcinoma and an decreased risk of esophageal ade- 
- Table 6 Sensitivity, specificity, positive and negative predictive value of every referral indication for different endoscopic outcome categories.

\begin{tabular}{|c|c|c|c|c|c|}
\hline $\begin{array}{l}\text { Referral } \\
\text { indication }\end{array}$ & Outcome of endoscopy & Sensitivity (95\% Cl) & Specificity (95\% Cl) & PPV (95\% CI) & NPV (95\% CI) \\
\hline \multirow{3}{*}{$\begin{array}{l}\text { Indication ac- } \\
\text { cording to the } \\
\text { NHG guideline }\end{array}$} & Malignant & $96.2 \%(90.4 \%-98.9 \%)$ & $42.4 \%(40.2 \%-44.7 \%)$ & $8.4 \%(8.0 \%-8.8 \%)$ & $99.5 \%(98.7 \%-99.8 \%)$ \\
\hline & Benign with clinical relevance & $68.0 \%(63.2 \%-72.7 \%)$ & $42.5 \%(40.0 \%-44.9 \%)$ & $22.1 \%(20.8 \%-23.5 \%)$ & $84.7 \%(82.6 \%-86.6 \%)$ \\
\hline & Benign without clinical relevance & $54.9 \%(52.3 \%-57.4 \%)$ & $26.0 \%(22.2 \%-30.1 \%)$ & $69.5 \%(68.1 \%-71.0 \%)$ & $15.8 \%(13.8 \%-18.0 \%)$ \\
\hline \multirow{3}{*}{$\begin{array}{l}\text { Alarm symp- } \\
\text { toms overall }\end{array}$} & Malignant & $90.4 \%(83.0 \%-95.3 \%)$ & $63.0 \%(60.8 \%-65.2 \%)$ & $11.8 \%(10.9 \%-12.7 \%)$ & $99.2 \%(98.5 \%-99.5 \%)$ \\
\hline & Benign with clini & $51.6 \%(46.5 \%-56.6 \%)$ & $63.1 \%(60.7 \%-65.5 \%)$ & $25.1 \%(23.0 \%-27.3 \%)$ & $84.5 \%(83.0 \%-85.8 \%)$ \\
\hline & Benign without clinical relevance & $33.2 \%(30.9 \%-35.7 \%)$ & $40.2 \%(35.9 \%-44.7 \%)$ & $63.1 \%(60.7 \%-65.5 \%)$ & $16.4 \%(14.9 \%-18.0 \%)$ \\
\hline \multirow[t]{3}{*}{ Dysphagia } & Malignant & $36.5 \%(27.3 \%-46.6 \%)$ & $79.9 \%(78.0 \%-81.7 \%)$ & $9.1 \%(7.1 \%-11.5 \%)$ & $95.8 \%(95.2 \%-96.4 \%)$ \\
\hline & Benign with cliı & $29.1 \%(24.6 \%-33.9 \%)$ & $81.0 \%(79.0 \%-82.9 \%)$ & $26.9 \%(23.4 \%-30.7 \%)$ & $82.7 \%(81.7 \%-83.6 \%)$ \\
\hline & Benign withc & $17.8 \%(15.9 \%-19.8 \%)$ & $69.3 \%(65.0 \%-73.4 \%)$ & $64.1 \%(60.0 \%-67.9 \%)$ & $21.5 \%(20.5 \%-22.6 \%)$ \\
\hline \multirow[t]{3}{*}{ Weight loss } & Malignant & $9.6 \%(4.7 \%-17.0 \%)$ & $95.1 \%(94.0 \%-96.0 \%)$ & $9.6 \%(5.4 \%-16.5 \%)$ & $95.1 \%(94.8 \%-95.4 \%)$ \\
\hline & Benign with clinical relevance & $5.4 \%(3.4 \%-8.2 \%)$ & $94.9 \%(93.7 \%-95.9 \%)$ & $20.2 \%(13.7 \%-28.8 \%)$ & $80.7 \%(80.3 \%-81.1 \%)$ \\
\hline & Benign witho & $4.8 \%(3.8 \%-6.0 \%)$ & $93.7 \%(91.2 \%-95.7 \%)$ & $70.2 \%(61.0 \%-78.0 \%)$ & $24.2 \%(23.7 \%-24.7 \%)$ \\
\hline \multirow{3}{*}{$\begin{array}{l}\text { Gastrointesti- } \\
\text { nal bleeding }\end{array}$} & Malignant & $3.9 \%(1.1 \%-9.6 \%)$ & $95.4 \%(94.3 \%-96.3 \%)$ & $4.4 \%(1.7 \%-10.8 \%)$ & $94.8 \%(94.6 \%-95.0 \%)$ \\
\hline & Benign with clinical relevance & $5.7 \%(3.6 \%-8.5 \%)$ & $95.7 \%(94.6 \%-96.6 \%)$ & $23.9 \%(16.5 \%-33.4 \%)$ & $80.9 \%(80.5 \%-81.3 \%)$ \\
\hline & Benign witho & $4.4 \%(3.4 \%-5.5 \%)$ & $94.7 \%(92.4 \%-96.5 \%)$ & $71.7 \%(62.0 \%-79.8 \%)$ & $24.4 \%(23.9 \%-24.8 \%)$ \\
\hline \multirow[t]{3}{*}{ Anemia } & Malignant & $1.9 \%(0.2 \%-6.8 \%)$ & $98.5 \%(97.8 \%-99.0 \%)$ & $6.5 \%(1.6 \%-22.2 \%)$ & $94.8 \%(94.7 \%-95.0 \%)$ \\
\hline & Benign with & $2.3 \%(1.1 \%-4.4 \%)$ & $98.6 \%(98.0 \%-99.2 \%)$ & $29.0 \%(16.0 \%-46.9 \%)$ & $80.8 \%(80.6 \%-81.1 \%)$ \\
\hline & Benign without clinical relevance & $1.3 \%(0.8 \%-2.0 \%)$ & $97.8 \%(96.0 \%-98.9 \%)$ & $64.5 \%(46.7 \%-79.0 \%)$ & $24.4 \%(24.1 \%-24.6 \%)$ \\
\hline \multirow{3}{*}{$\begin{array}{l}\text { Dysphagia and } \\
\text { weight loss }\end{array}$} & Malignant & $32.7 \%(23.8 \%-42.6 \%)$ & $95.4 \%(94.4 \%-96.3 \%)$ & $28.1 \%(21.7 \%-35.5 \%)$ & $96.3 \%(95.8 \%-96.7 \%)$ \\
\hline & Benign with & $7.2 \%(4.9 \%-10.3 \%)$ & $94.3 \%(93.0 \%-95.3 \%)$ & $23.1 \%(16.7 \%-31.2 \%)$ & $80.9 \%(80.4 \%-81.4 \%)$ \\
\hline & Benign without clinical relevance & $3.9 \%(3.0 \%-5.0 \%)$ & $87.4 \%(84.1 \%-90.2 \%)$ & $48.8 \%(40.3 \%-57.3 \%)$ & $22.8 \%(22.2 \%-23.4 \%)$ \\
\hline \multirow{3}{*}{$\begin{array}{l}\text { Weight loss } \\
\text { and gastroin- } \\
\text { testinal } \\
\text { bleeding }\end{array}$} & Malignant & $1.0 \%(0.02 \%-5.2 \%)$ & $99.4 \%(99.0 \%-99.7 \%)$ & $8.3 \%(1.2 \%-41.1 \%)$ & $94.8 \%(94.7 \%-94.9 \%)$ \\
\hline & Benign with $c$ & $1.0 \%(0.3 \%-2.6 \%)$ & $99.5 \%(99.0 \%-99.8 \%)$ & $33.3 \%(13.1 \%-62.3 \%)$ & $80.7 \%(80.6 \%-80.9 \%)$ \\
\hline & Benign without clinical relevance & $0.5 \%(0.2 \%-1.0 \%)$ & $99.0 \%(97.6 \%-99.7 \%)$ & $58.3 \%(30.9 \%-81.5 \%)$ & $24.4 \%(24.3 \%-24.6 \%)$ \\
\hline \multirow{3}{*}{$\begin{array}{l}\text { Dyspepsia } \\
>50 \text { years of } \\
\text { age, HP nega- } \\
\text { tive }\end{array}$} & Malignant & $5.8 \%(2.2 \%-12$ & $80.2 \%(78.3 \%-82.0 \%)$ & $1.6 \%(0.7 \%-3.4 \%)$ & $94.0 \%(93.7 \%-94.3 \%)$ \\
\hline & Benign with clinical relevance & $16.0 \%(12.5 \%-20.0 \%)$ & $80.2 \%(78.1 \%-82.1 \%)$ & $16.2 \%(13.1 \%-19.9 \%)$ & $79.9 \%(79.1 \%-80.7 \%)$ \\
\hline & Benign with & $20.8 \%(18.8 \%-22.9 \%)$ & $86.2 \%(82.8 \%-89.1 \%)$ & $82.3 \%(78.4 \%-85.5 \%)$ & $26.1 \%(25.3 \%-27.0 \%)$ \\
\hline \multirow[t]{3}{*}{ Other } & Malignant & $4.8 \%(1.6 \%-10.9 \%)$ & $98.6 \%(97.9 \%-99.1 \%)$ & $15.6 \%(6.8 \%-32.0 \%)$ & $95.0 \%(94.8 \%-95.2 \%)$ \\
\hline & Benign with clinical relevance & $1.3 \%(0.4 \%-3.0 \%)$ & $98.3 \%(97.6 \%-98.9 \%)$ & $15.6 \%(6.7 \%-32.3 \%)$ & $80.6 \%(80.4 \%-80.8 \%)$ \\
\hline & Benign without clinical relevance & $1.5 \%(0.9 \%-2.2 \%)$ & $98.0 \%(96.3 \%-99.0 \%)$ & $68.8 \%(51.2 \%-82.2 \%)$ & $24.4 \%(24.2 \%-24.7 \%)$ \\
\hline \multirow{3}{*}{$\begin{array}{l}\text { Indication not } \\
\text { according to } \\
\text { the NHG } \\
\text { guideline }\end{array}$} & Malignant & $3.9 \%(1.1 \%-9.6 \%)$ & $57.6 \%(55.3 \%-59.8 \%)$ & $0.5 \%(0.2 \%-1.3 \%)$ & $91.6 \%(91.2 \%-92.0 \%)$ \\
\hline & Benign with clinical relevance & $32.0 \%(27.3 \%-36.9 \%)$ & $57.5 \%(55.1 \%-60.0 \%)$ & $15.3 \%(13.4 \%-17.4 \%)$ & $77.9 \%(76.5 \%-79.3 \%)$ \\
\hline & Benign without clinical relevance & $45.1 \%(42.6 \%-47.7 \%)$ & $74.0 \%(69.9 \%-77.8 \%)$ & $84.2 \%(82.0 \%-86.2 \%)$ & $30.5 \%(29.0 \%-32.0 \%)$ \\
\hline \multirow{3}{*}{$\begin{array}{l}\text { Dyspepsia } \\
<50 \text { years of } \\
\text { age }\end{array}$} & Malignant & $0 \%$ & $80.4 \%(78.5 \%-82.2 \%)$ & $0 \%$ & $93.6 \%(93.5 \%-93.8 \%)$ \\
\hline & Benign with clinical relevance & $10.1 \%(7.3 \%-13.5 \%)$ & $79.4 \%(77.3 \%-81.3 \%)$ & $10.5 \%(7.9 \%-13.8 \%)$ & $78.6 \%(77.9 \%-79.3 \%)$ \\
\hline & Benign without $\mathrm{c}$ & $22.1 \%(20.0 \%-24.2 \%)$ & $92.1 \%(89.3 \%-94.3 \%)$ & $89.5 \%(86.2 \%-92.2 \%)$ & $27.7 \%(27.0 \%-28.5 \%)$ \\
\hline \multirow{3}{*}{$\begin{array}{l}\text { Dyspepsia } \\
>50 \text { years of } \\
\text { age, HP un- } \\
\text { known }\end{array}$} & Malignant & $3.9 \%(1.1 \%-9.6 \%)$ & $77.8 \%(75.8 \%-79.6 \%)$ & $0.94 \%(0.36 \%-2.42 \%)$ & $93.7 \%(93.4 \%-93.9 \%)$ \\
\hline & Benign with clinical relevance & $21.1 \%(17.2 \%-25.5 \%)$ & $78.7 \%(76.6 \%-80.7 \%)$ & $19.2 \%(16.1 \%-22.7 \%)$ & $80.6 \%(79.7 \%-81.5 \%)$ \\
\hline & Benign without clinical relevance & $22.5 \%(20.4 \%-24.7 \%)$ & $82.5 \%(78.9 \%-85.8 \%)$ & $79.9 \%(76.2 \%-83.1 \%)$ & $25.7 \%(24.8 \%-26.7 \%)$ \\
\hline
\end{tabular}


- Table 6 (Continuation)

\begin{tabular}{|l|l|l|l|l|l|}
\hline $\begin{array}{l}\text { Referral } \\
\text { indication }\end{array}$ & Outcome of endoscopy & Sensitivity (95\% Cl) & Specificity (95\% CI) & PPV (95\% Cl) & NPV (95\% Cl) \\
\hline \multirow{2}{*}{ Other } & Malignant & $0 \%$ & $99.4 \%(99.0 \%-99.7 \%)$ & $0 \%$ & $94.8 \%(94.8 \%-94.8 \%)$ \\
\hline & Benign with clinical relevance & $0.8 \%(0.2 \%-2.2 \%)$ & $99.5 \%(99.0 \%-99.8 \%)$ & $27.3 \%(9.1 \%-58.5 \%)$ & $80.7 \%(80.6 \%-80.9 \%)$ \\
\hline & Benign without clinical relevance & $0.5 \%(0.2 \%-1.0 \%)$ & $99.4 \%(98.2 \%-99.9 \%)$ & $72.7 \%(41.5 \%-90.9 \%)$ & $24.5 \%(24.4 \%-24.7 \%)$ \\
\hline
\end{tabular}

Only the indications occurring with a frequency $>0.5 \%$ were extensively reported.

- Table 7 Uni- and multivariate logistic regression of possible predictors for upper gastrointestinal malignancy.

Malignancy of the upper gastrointestinal tract

\begin{tabular}{|c|c|c|c|c|c|c|}
\hline \multirow[b]{2}{*}{ Possible predictors } & \multicolumn{3}{|c|}{ Univariate analyse } & \multicolumn{3}{|c|}{ Multivariate analyse } \\
\hline & OR & $95 \% \mathrm{Cl}$ & $P$ value & OR & $95 \% \mathrm{Cl}$ & $P$ value \\
\hline Alarm symptoms & 16.032 & $8.298-30.974$ & $<0.0001$ & 10.488 & $5.276-20.849$ & $<0.0001$ \\
\hline Age & 1.071 & $1.052-1.090$ & $<0.0001$ & 1.051 & $1.032-1.071$ & $<0.0001$ \\
\hline \multicolumn{7}{|l|}{ Gender } \\
\hline - Female & Reference & & & & & \\
\hline - Male & 4.481 & $2.796-7.183$ & $<0.0001$ & 3.942 & $2.401-6.473$ & $<0.0001$ \\
\hline \multicolumn{7}{|l|}{ PPI or H2RA use } \\
\hline - Yes & Reference & & & & & \\
\hline - No & 1.828 & $1.193-2.802$ & 0.006 & 0.769 & $0.484-1.221$ & 0.266 \\
\hline \multicolumn{7}{|l|}{ HP status } \\
\hline - Negative & Reference & & & & & \\
\hline - Positive & 0.825 & $0.191-3.569$ & 0.797 & & & \\
\hline \multicolumn{7}{|l|}{ Sedation } \\
\hline - Yes & 0.810 & $0.541-1.214$ & 0.308 & & & \\
\hline - No & Reference & & & & & \\
\hline
\end{tabular}

nocarcinoma [21,22]. However, dramatic increases in gastric and esophageal adenocarcinoma rates in several Western countries parallel the declines in $\mathrm{H}$. pylori infection rates [22]. Due to the retrospective nature of this study and the discrepancy in the literature we could only speculate what the role of a $\mathrm{H}$. pylori infection was in the observed malignancies. If dyspepsia above the age of 50 is considered an appropriate indication no malignancies would be missed, however, the cost effectiveness of OAE would rapidly decrease. Before any changes in the NHG guideline are made, more prospective studies are needed addressing the relationship between a $\mathrm{H}$. pylori infection and a malignant finding in OAE.

The current study showed that the PPV of alarm symptoms for detecting a malignancy is considerably higher compared to other studies (11.8\% versus $5.9 \%$ ). Especially patients with the alarm symptoms dysphagia and weight loss combined had a relatively high PPV of $28.1 \%$ ( $\triangleright$ Table 5 ). The NPV is $99.2 \%$ which is corresponding with a meta-analysis which showed a pooled
NPV for alarm symptoms of 99.4\% [23]. Our analysis showed that age, male gender and alarm symptoms are significant predictive variables for upper gastrointestinal malignancies. The combination of these variables resulted in an AUC of 0.868 for detecting upper GI malignancies, therewith higher than a similar Finnish study (AUC=0.72) [24]. Our risk-prediction model (age, alarm symptoms and male gender) gives the same AUC as the risk-prediction model made by Khademi et al. (AUC = 0.85 ) which was based on different independent variables (age, alarm symptoms and smoking) [25]. Due to missing data, we could not include cigarette smoking in our risk prediction model, but this previous study suggests that our AUC could possibly become even higher by including this variable. Our study suggests that in female patients without alarm symptoms the age threshold for performing OAE could be safely raised compared to male patients.

The aim of OAE is to ensure rapid detection of upper gastrointestinal malignancy and to provide an effective way of mana- 


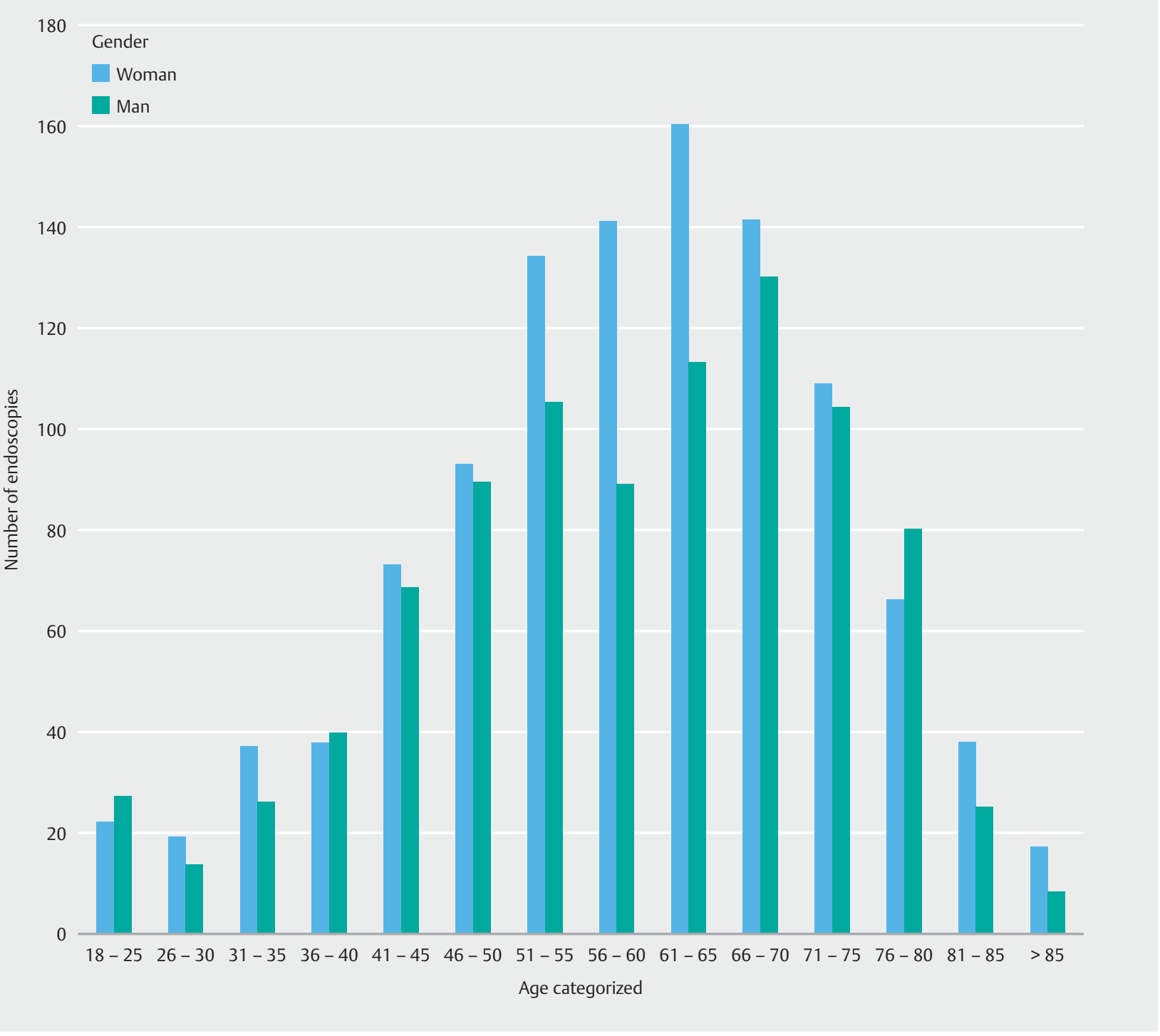

- Fig. 1 Number of OAEs performed in different age groups.

ging patients without a malignancy. In our study, there was no malignancy found in patients under the age of 40 years and more than $90 \%$ of the patients with a malignancy had 1 or more alarm symptoms ( $\mathbf{F i g . 2}$ ). Our study is consistent with others who found that upper gastrointestinal cancer was rare in patients under the age of 45 and all patients had alarm symptoms at presentation [26]. In contradiction, 1 study showed that $0.3 \%$ of the malignancies were detected in patients under the age of 45 who presented with uncomplicated dyspepsia [27]. However, it is uncertain whether an earlier diagnosis would alter clinical outcome, as studies showed that patients with a malignancy under the age of 55 years presented with uncomplicated dyspepsia had lymph node metastasis at diagnosis $[27,28]$. The authors concluded that increasing the age limit of OAE to 55 years in patients with uncomplicated dyspeptic symptoms would unlikely affect clinical consequences, given the inoperable stage of the tumors in this younger patient group $[27,28]$. These and our results support the opinion that patients without alarm symptoms under the age of 50 year can be treated without OAE, which is concordant with the indications mentioned in the NHG guideline [24]. It even suggests that you can treat patients under the age of 40 without OAE, irrespectively of alarm symptoms. This with a low risk of missing a curable malignancy of the upper gastrointestinal tract. Important to notice is that this age threshold is only applicable to the Dutch community because it is determined by local epidemiological factors (ethnic background and prevalence of $\mathrm{H}$. pylori).

In our study OAE is unnecessary (no clinical relevant finding) in $88.3 \%$ of dyspeptic patients under the age of 45 , even $50 \%$ had a normal endoscopy. Our results were consistent with studies which found that OAE is unnecessary in approximately $75 \%$ of young dyspeptics $[29,30]$. Yet, in our study $16 \%$ of the OAE are performed in this age group, in other studies this number rises to even a third of all endoscopies [26, 31]. A reduction of this number of unnecessary OAEs can be crucial to the cost ef- 


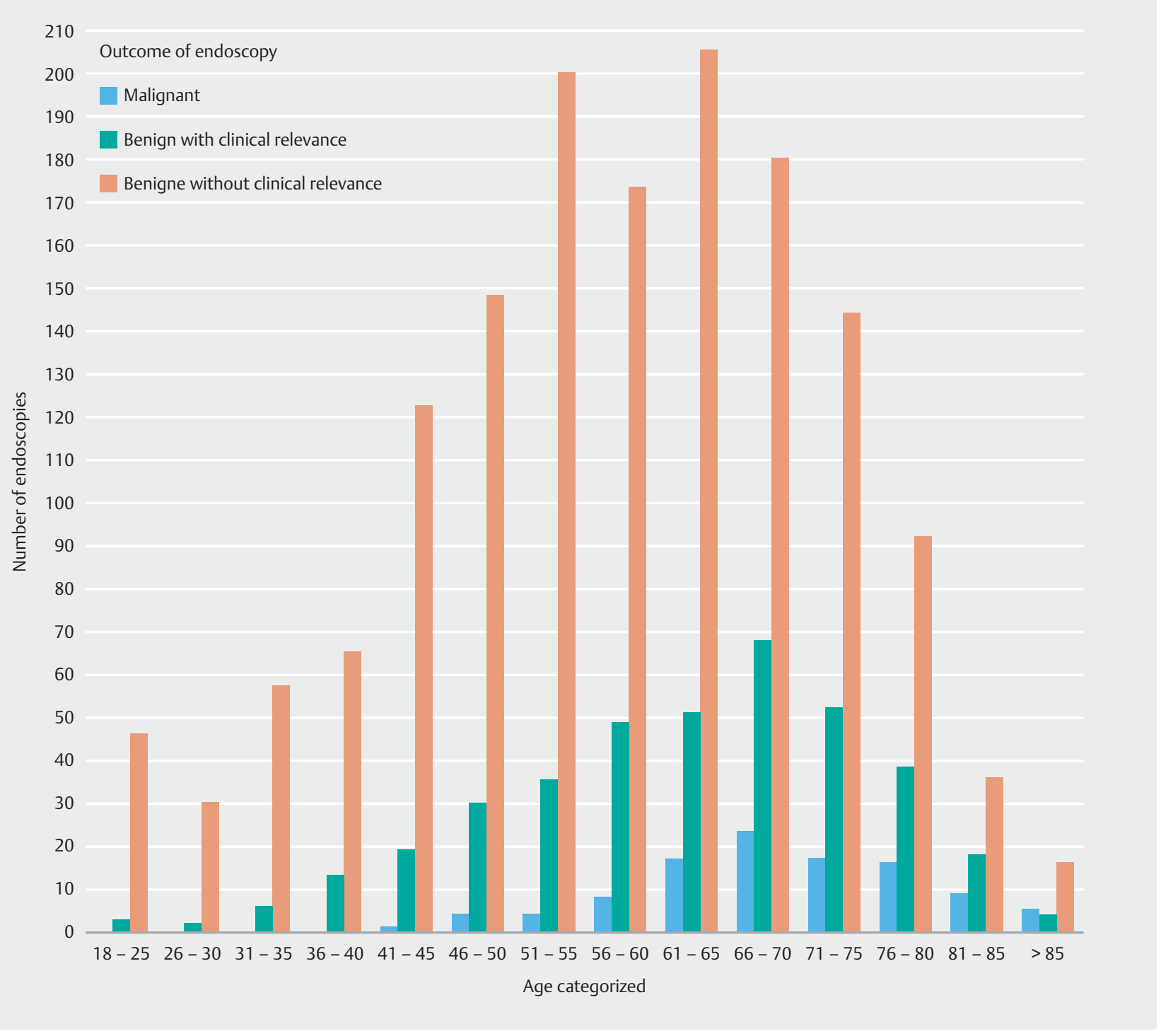

Fig. 2 Outcome of endoscopy in different age groups.

fectiveness of the open-access system. In addition, evidence suggest that most patients with reflux symptoms are, regardless of the endoscopic findings, switched to acid suppressive therapy $[32,33]$. This may suggest that the management of symptoms is hardly influenced by the OAE. However, a normal endoscopy cannot simply be devalued, it may have changed the treatment course of some patients. 1 study showed that $67 \%$ of the normal endoscopies assisted the caring physicians whether to continue with medication or to proceed with other investigations, and to help reassure patients [34]. Furthermore, some studies demonstrated that a normal endoscopy led to a better quality of life and patient satisfaction [17, 35]. In contradiction, other studies showed that quality of life was only improved during a short period after a negative endoscopy and there was no difference in experienced quality of life between prompt endoscopy or empirical treatment with acid suppressive therapy after 1 year $[36,37]$.
Our retrospective study had certain limitations. Firstly, indications for OAE were based on information provided by the GP, consequently, appropriateness of the indication could be underestimated or overestimated. This is, nevertheless, always the case in an open-access system. Secondly, because of the sometimes brief referral letter some data were missing. For example, it is unclear how long in advance the acid inhibition has been stopped and whether it has been stopped at all. This could, possibly, have masked some organic disorders. We think, however, that clinical relevant findings would still be detected by OAE, irrespectively of PPI use. Lastly, we did not include histological analysis of normal mucosa, which could lead to a diagnosis of celiac disease, and therefore clinical relevance. 


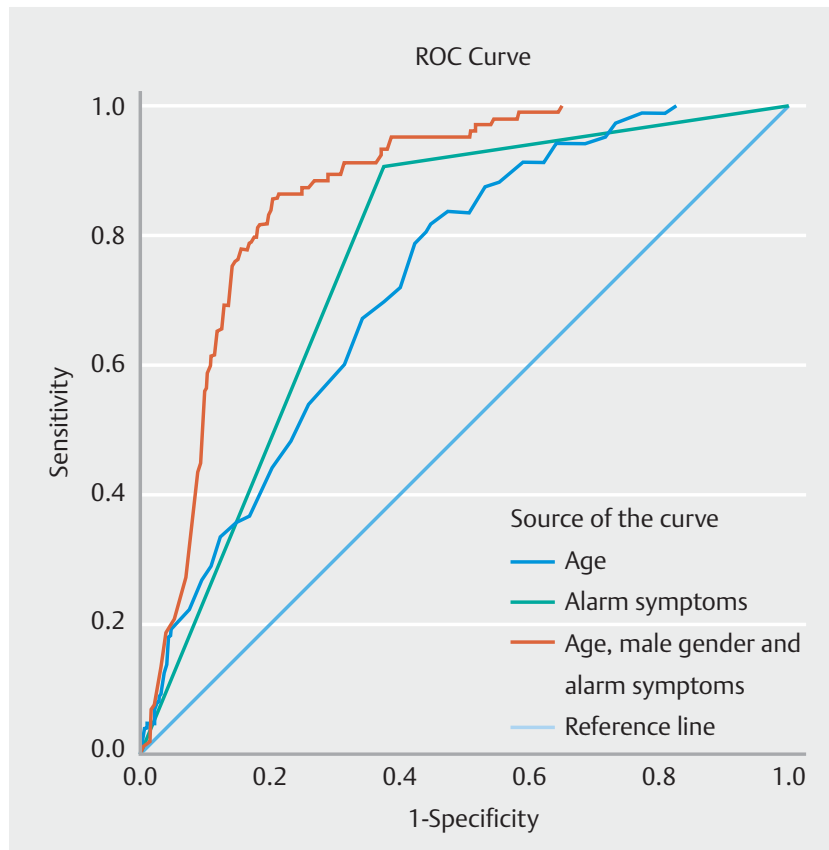

Diagonal segments are produced by ties

- Fig. 3 Receiver operating characteristic (ROC) curve comparing the accuracy of age alone $(A \cup C=0.729)$, alarm symptoms alone $(A \cup C=0.767)$ and age, alarm symptoms and male gender combined ( $A \cup C=0.868$ ) in predicting a malignant finding in OAE.

\section{Conclusion}

In conclusion, we found a high rate of malignant findings and only $3.8 \%$ of the malignancies would be missed by strict adherence to the guideline. This indicates that the open-access system in the Netherlands works well. Further improvement of the open-access system can be achieved by streamlining of the referrals by the endoscopy unit by only accepting appropriate indications for OAE. Our results even suggest that patients under the age of 40 can be treated without OAE, irrespectively of alarm symptoms, with a very low risk of missing a curable malignancy. We showed that a risk-prediction model based on the variables age, alarm symptoms and male gender is a good predictor of malignant finding. This suggests that gender should be adopted in guidelines besides age and alarm symptoms which may lead to a different age cut-off point for performing OAEs in men and women.

\section{Competing interests}

\section{None}

\section{References}

[1] Van Kerkhoven LAS, Van Rijswijck SJ, Van Rossum LGM et al. Openaccess upper gastrointestinal endoscopy a decade after the introduction of proton pump inhibitors and Helicobacter pylori eradication: A shift in endoscopic findings. Digestion 2007; 75: 227-31
[2] Talley NJ, Vakil N, Delaney B et al. Management issues in dyspepsia: Current consensus and controversies. Scand J Gastroenterol 2004; 39 : 913-918

[3] Buri L, Bersani G, Hassan C et al. How to predict a high rate of inappropriateness for upper endoscopy in an endoscopic centre? Dig Liver Dis 2010; 42: 624-628

[4] Chan YM, Goh KL. Appropriateness and diagnostic yield of EGD: A prospective study in a large Asian hospital. Gastrointest Endosc 2004; 59: $517-524$

[5] Numans ME, De Wit N], Dirven JAM et al. NHG-Standaard Maagklachten (derde herziening). 2013: https://www.nhg.org/standaarden/ volledig/nhg-standaard-maagklachten-derde-herziening

[6] Broe M, Barry M, Patchett S et al. Evaluating the clinical efficacy and cost effectiveness of direct access endoscopy. Surgeon 2013; 11 : $304-308$

[7] Boulton-Jones JR, Follows MC, Mahmoud AA. Open-access endoscopy: Are age-based guidelines justified? An audit of experience of 1000 open-access endoscopies at a district general hospital Endoscopy 2003; 35: $68-73$

[8] Keren D, Rainis T, Stermer E et al. A nine-year audit of open-access upper gastrointestinal endoscopic procedures: Results and experience of a single centre. Can J Gastroenterol 2011; 25: 83-88

[9] Mangualde J, Cremers MI, Vieira AM et al. Appropriateness of outpatient gastrointestinal endoscopy in a non-academic hospital. World J Gastrointest Endosc 2011; 3: 195-200

[10] Manes G, Balzano A, Marone P et al. Appropriateness and diagnostic yield of upper gastrointestinal endoscopy in an open-access endoscopy system: A prospective observational study based on the Maastricht guidelines. Aliment Pharmacol Ther 2002; 16: 105-110

[11] Salo M, Collin P, Kyronpalo S et al. Age, symptoms and upper gastrointestinal malignancy in primary care endoscopy. Scand J Gastroenterol 2008; 43: $122-127$

[12] Numans ME, van der Graaf Y, De Wit NJ et al. How useful is selection based on alarm symptoms in requesting gastroscopy? An evaluation of diagnostic determinants for gastro-oesophageal malignancy Scand J Gastroenterol 2001; 36: 437-443

[13] Vakil N, Moayyedi P, Fennerty MB et al. Limited value of alarm features in the diagnosis of upper gastrointestinal malignancy: systematic review and meta-analysis. Gastroenterology 2006; 131: 390 -401

[14] Integraal kanker centrum Nederland.www.cijfersoverkanker.nl

[15] Di Giulio E, Hassan C, Marmo R et al. Appropriateness of the indication for upper endoscopy: a meta-analysis. Dig Liver Dis 2010; 42: 122 126

[16] Hassan C, Bersani G, Buri L et al. Appropriateness of upper-Gl endoscopy: an Italian survey on behalf of the Italian Society of Digestive Endoscopy. Gastrointest Endosc 2007; 65: 767-774

[17] Aljebreen AM, Alswat K, Almadi MA. Appropriateness and diagnostic yield of upper gastrointestinal endoscopy in an open-access endoscopy system. Saudi J Gastroenterol 2013; 19: 219-222

[18] Trevisani L, Sartori S, Gilli G et al. Appropriateness of upper gastrointestinal endoscopy: A hospital-based study. Dig Dis Sci 2001; 46: $2695-2699$

[19] Rossi A, Bersani G, Ricci G et al. ASGE guidelines for the appropriate use of upper endoscopy: association with endoscopic findings. Gastrointest Endosc 2002; 56: 714-719

[20] Shekelle PG. Are appropriateness criteria ready for use in clinical practice? N Engl J Med 2001; 344: 677-678

[21] Group CC. Gastric cancer and Helicobacter pylori : a combined analysis of 12 case control studies nested within prospective cohorts. Gut 2001; 49: 347-353

[22] Islami F, Kamangar F. Helicobacter pylori and Esophageal Cancer Risk - A Meta- Analysis. Cancer Prev Res 2008; 1: 329-338 
[23] Fransen GAJ, Janssen MJR, Muris JWM et al. Meta-analysis: The diagnostic value of alarm symptoms for upper gastrointestinal malignancy. Aliment Pharmacol Ther 2004; 20: 1045-1052

[24] Voutilainen M, Mäntynen T, Mauranen K et al. Is it possible to reduce endoscopy workload using age, alarm symptoms and $\mathrm{H}$. pylori as predictors of peptic ulcer and oesophagogastric cancers? Dig Liver Dis 2005; 37: $526-532$

[25] Khademi H, Radmard AR, Malekzadeh F et al. Diagnostic accuracy of age and alarm symptoms for upper GI malignancy in patients with dyspepsia in a Gl clinic: A 7-year cross-sectional study. PLoS One 2012; 7: $1-10$

[26] Williams B, Luckas M, Ellingham JH. Do young patients with dyspepsia need investigation? Lancet (London, England) 1988; 8624: 1349 1351

[27] Canga C, Vakil N. Upper Gl malignancy, uncomplicated dyspepsia, and the age threshold for early endoscopy. Am J Gastroenterol 2002; 97: $600-603$

[28] Gillen D, McColl KEL. Does concern about missing malignancy justify endoscopy in uncomplicated dyspepsia in patients aged less than 55 ? Am J Gastroenterol 1999; 94: 75-79

[29] Lassen AT, Pedersen FM, Bytzer P. Helicobacter pylori test-and-eradicate versus prompt endoscopy for managment of dyspeptic patients: A randomised trial. Lancet (London, England) 2000; 356: 455-460

[30] Heaney A, Collins JSA, Watson RG. A prospective randomised trial of a 'test and treat' policy versus endoscopy based management in young
Helicobacter pylori positive patients with ulcer-like dyspepsia, referred to a hospital clinic. Gut 1999; 45: $186-190$

[31] Marmo R, Rotondano G, Piscopo R et al. Combination of age and sex improves the ability to predict upper gastrointestinal malignancy in patients with uncomplicated dyspepsia: A prospective multicentre database study. Am J Gastroenterol 2005; 100: 784 - 791

[32] Van Kerkhoven LAS, Van Rijswijck SJ, Van Rossum LGM et al. Is there any association between referral inidcations for open-access upper gastrointestinal endoscopy and endoscopic findings? Endoscopy 2007; 39: $502-506$

[33] Blustein PK, Beck PL, Meddings JB. The ultility of endoscopy in the management of patients with gastroesophageal reflux symptoms. Am J Gastroenterol 1998; 93: 2508-2512

[34] Naji SA, Brunt PW, Hagen S et al. Improving the selection of patients for upper gastrointestinal endoscopy. Gut 1993; 34: 187-191

[35] Rabeneck L, Wristers K, Souchek J et al. Impact of upper endoscopy on satisfaction in patients with previously uninvestigated dyspepsia. Gastrointest Endosc 2003; 57: 295-299

[36] Wiklund I, Glise H, Jerndal P et al. Does endoscopy have a positive impact on quality of life in dyspepsia? Gastrointest Endosc 1998; 47: $449-454$

[37] Bytzer P, Hansen JM, Schaffalitzky de Muckadell OB. Emperical H2blocker therapy or prompt endoscopy in management of dyspepsia. Lancet (London, England) 1994; 343: 811-816 